\title{
PUT A CHECK-UP IN YOUR TROLLEY
}

The first NHS dental practice to be based in a supermarket in England has been opened in Bedford by Integrated Dental Holdings (IDH).

The new practice opened in June at Tesco Bedford Riverfield Drive Superstore and is open every day, enabling patients to register in-store and get an appointment quickly. The dental team consists of three dentists, six dental nurses, one hygienist, a receptionist and a practice

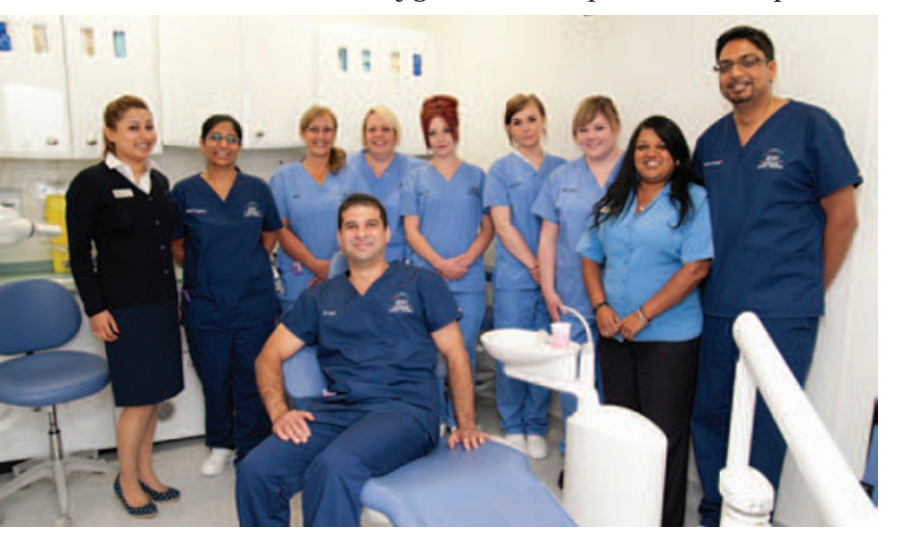

\section{NEW PATHS TO DENTAL SCHOOL}

Specialist private medical college Medipathways has launched a new two-year honours degree programme in Biomedical Science, the first of its kind in the UK, designed specifically for medical or dental school entry.

While studying with Medipathways on the Birkbeck campus in London (the degree is validated by the University of Buckingham), students will receive special attention for their UKCAT/BMAT, work experience and interview preparations, optimising their chances for entry to medical school. Students can also apply for UK medical or dental school after just the first year. This gives students three opportunities for gaining entry to medical or dental school over a two-year period; a traditional three year BSc route only allows for two opportunities.

To find out more visit www.medipathways.com. manager - a team originally located in a community centre in Bedford.

Shazna Bibi, practice manager at the superstore practice, said: 'Patients have been enthusiastic about the new practice and many people have admired our facilities. Our location in the Tesco Superstore is terrific and patients have told us how convenient it is. We used to be booked for weeks before patients could secure an appointment, but now it's much easier to see them as we have open books, more dentists and the availability of evening and weekend appointments. Patients can also see a hygienist without seeing a dentist first. We offer private dental treatments too, so patients can easily find out about the available options while in store.'

\section{STOP PRESS: SUGAR COULD AID CANCER FIGHT}

Sugar rarely receives positive press - particularly in the $B D J$ - but according to researchers in San Francisco, a natural form of sugar could offer a new, non-invasive way to precisely image tumours and potentially see whether cancer medication is effective.

A new imaging technology developed at UC San Francisco in collaboration with GE Healthcare uses a compound called pyruvate, which is created when glucose breaks down in the body and which normally supplies energy to cells. In cancer, pyruvate is more frequently converted to lactate. Previous animal studies showed that scientists could track the levels of pyruvate converted to lactate via magnetic resonance imaging (MRI), by using a technology called hyperpolarisation and injecting the hyperpolarised pyruvate into the body. The amount of lactate produced and rate of conversion enabled researchers to precisely detect the limits of a mouse's tumour, identify which cancers were most aggressive and track early biochemical changes as tumours responded to medication, long before physical changes occurred.

Now, a 31-patient study performed by scientists at UCSF and their collaborators has shown that the technology is safe in humans and effectively detects tumours in patients with prostate cancer. ${ }^{1}$

This first in vivo human study lays the groundwork for using the technology to diagnose a variety of cancers and track treatment non-invasively, without conducting repeated biopsies.

1. Nelson S J, Kurhanewicz J, Vigneron D B et al. Metabolic imaging of patients with prostate cancer using hyperpolarized [1-13C] pyruvate. Sci Transl Med 2013; 14: 198ra108.

\section{DIARY}

BDA Community Dental Services Group - Annual Presidential and Scientific Meeting 2013

Date: 9-11 October 2013 Venue: Hilton Cardiff, Cardiff Telephone: 02075634590

Email: events@bda.org www.bda.org/groups

Tooth wear and erosion

Date: 11 October 2013

Venue: Hilton Liverpool Hotel,

Liverpool

Telephone: 02075634590

Email: events@bda.org www.bda.org/seminars

BDTA Dental Showcase

Date: 17-19 October 2013

Venue: NEC Birmingham

www.dentalshowcase.com

Bridge2Aid Bash

(live band, disco, hot buffet)

Date: 18 October 2013

Venue: Hilton Metropole,

Birmingham

Telephone: 08458509877

Email: thebash@bridge2aid.org

www.bridge2aid.org

Dentech China 2013

Date: 23-26 October 2013

Location: Shanghai

www.dentech.com.cn

The Dentist as Artist-Technician by Jason Smithson

Date: 8 November 2013

Location: BACD 10th Annual

Conference, Hilton London

Metropole

Telephone: 02076124166

www.bacd.com

BSDHT Oral Health Conference Date: 15-16 November 2013

Venue: International Conference

Centre, Birmingham

Email: enquiries@bsdht.org.uk

www.bsdht.org.uk

DPL Premier Symposium

Date: 23 November 2013

Venue: The Shaw Theatre, London

Telephone: 02073992914

Email: events@dentalprotection.org

9th International Vienna

Orthodontic Symposium (IVOS)

Date: 6-7 December 2013

Venue: Österreichische Akademie

der Wissenschaften, Vienna

www.ivos.at 